\title{
IMPACT OF NIGERIA SOCIAL MEDIA INFLUENCERS ON THEIR FOLLOWERS IN ONLINE COMMUNITY
}

\author{
Olatilewa Olaojo \\ Department of Mass Communication, \\ University of Ilorin, Nigeria \\ Olaojoolatilewa16@gmail.com \\ $+2348169007104$
}

\begin{abstract}
The main aim of this research was to investigate the Nigerian influencers and their influence on their followers in an online community - Twitter. The study adopted a mixed method comprising of online social media followers and a content analysis of influencers' posts across three themes of interest: marketing, political and advocacy. The specific objectives of the study were to: (i) determine whether influencers with high personality attributes exert more significant influence on their followers than those with low personality traits; (ii) determine whether influencers with high personality traits and social characteristics have more significant reliability and thus exert greater influence on their followers than those with lower personality traits, social attributes and lower credibility; (iii) examine if there is a significant relationship between influencers' communication ability and the impact they have on their followers; and (iv) examine the difference between the level of impact that political influencers have on their followers than marketing influencers. Data were analyzed using descriptive and inferential statistics at 0.05 significance. The findings of the study were that: (i) the frequently used communication strategy employed by the influencers is informative $(6,42.9 \%)$ to influence their followers; (ii) personality attributes of all categories of influencers had a significant effect on the extent of influence their online activities exert on their followers; and there was no significant difference between the level of impact political influencers had on their followers compared to what marketing influencers had on theirs. The study therefore recommended that media literacy among youths should be enhanced to increase their capacity for following influencers reasonably.
\end{abstract}

Keywords: Influencers; Twitter; Marketing, Personality attribute; Social attribute

\section{INTRODUCTION}

Recently, with the events revolving around the internet and social media since its invention, it has become the wonder of the communication world. A lot of activities and phenomena take place through them. One of such wonders is online opinion leadership (influencers). They are the people who are very powerful because they exert a lot of influence on people. Nevertheless, they are individuals who have been found to exhibit specific characteristics or traits that mobilize or influence their followers. While the media play an essential role in developing and shaping public opinion, today, just anyone can assume this role on social media. The social media has lost its gatekeeping nature because it is easily manipulated by ordinary citizens who actively engage in the dual function of processing and disseminating information.

The concept of opinion leadership i.e. influencers or influentials was first introduced by Elihu Katz, and since then, it has been revisited in a cornucopia of studies across many academic disciplines (Katz, 1955). Weimann (1994) dismissed the term "opinion leader" because it suggests that the person has to have special leadership skills and abilities often associated with a formal leadership position. He preferred to address them as "influential". 
In Nigeria, opinion leaders in online community, now known as influencers, have been able to penetrate the visible areas such as political, advocacy (Bring Back Our Girls campaign) and voting pattern or behaviour (\#votenotfight, \#electionnotwar). The phenomenon of social media influencers has become so prevalent in Nigeria online community that there are now more than thousands of self-acclaimed and established online influencers with millions of followers on the Nigerian online community (Bello, 2018). This phenomenon of social media influencer has become very significant given the names of internet users in Nigeria today, which, according to Nigeria Communications Commission (NCC) report, the numbers of internet users was released as marginally 98.3million (Nigeria Communications Commission [NCC], 2018). Opinion leaders in various ways have emerged as influential members of online communities and have been ascertained to be a source of advice for other consumers. Nowadays, social media have become tools of greater influence wherein consumers actively garner information and make choices based on them (Casaló, Cisneros, Flavián, \&Guinalíu, 2009; Thakur, Agriawan, \&Summey, 2016).

One of the new media tool is the twitter which is the sole social media platform that is of interest in this study. A baseline review of the activities of the social media influencers in Nigeria, especially on Twitter, indicated that the influencers do not show any form of disparity as they all mix everything. This means that the influencers in Nigeria online community somewhat perform political, advocacy and even marketing roles interchangeably. However, there is a need to desegregate the Nigeria social media influencers to identify their categories and also to determine the extent of the influence each type exert on their followers Taking all this into account, in spite of all the studies conducted to understand the influencers, particularly in many Western countries' online communities, little or nothing is known about the emerging influence of the influencers in Nigeria online community.

Many previous studies on the use of social media among Nigerians had rather concentrated their efforts at describing social media, social media use by various political actors, explaining social media adaption rates or investigating the content created within the platforms (Akinlade, 2015; Chiemela, Ovute\&Obochi, 2015; Nnanyelugo \& Nwafor, 2013 cited in Ekwueme and Folarin 2017; Olasinde, 2014; Tokunbo\& Felix, 2013; Anyanwu, Ossai-Onah\&Iroeze, 2013). Few or no studies have systematically tried to develop a theoretical understanding of social media use that could explain the extent to which social media influencers in Nigeria online community change the political and social behaviour of their followers.

This research extends previous researches on opinion leadership on Twitter and it is specifically tailored to three objectives.

\section{THEORETICAL FRAMEWORK}

\section{Two-Step Flow Theory}

Given that the opinion leadership emanated from the Two-Step Flow theory, the theory states that the mass media messages are now mediated by specific individuals who are known as the opinion leaders now commonly referred to as influencers. Two-Step Flow theory is an effect theory which was founded by Paul Lazarsfeld, Bernard Berelson and Hazel Gaudet, (1944). Two-step flow theory posits that mass media do not directly influence individuals. Instead, mass media is filtered via a two-step process through influential community members with specialized interests who then control the individual (Anaeto, Onabajo\&Osifeso, 2008). 
Lazarsfeld, Berelson, and Gaudet (1944) cited in Kononova and Akbar (2015) established that political decision-making depends on interpersonal communication more than on mass media. Importantly, the concept of the Two-Step Flow theory suggests that the flow of information disseminated by mass media goes through two stages to reach recipients. First, from the mass media to certain people known as opinion leaders and, second, from these opinion leaders now known as influencers to the general populace. In relation to this study, it is understood that these social media influencers have a mastery of the mass media communicated messages so they can demonstrate high intelligence on it in order to achieve any goal intended.

Therefore, this study intends to extend the traditional opinion leadership framework to political activism on social media. Traditionally, opinion leaders have both greater access to information and more platforms for disseminating information.

\section{Source Credibility Theory}

This theory was introduced by Hovland, Janis, and Kelly in 1953. Source Credibility theory proposes that people are more likely to be persuaded when the source presents itself as credible. Using this theory to explain the forming of the influence of social media influentials on their community of followers as well, Self (2007, p. 435) described 'Source Credibility' as "the believability of a communicator as perceived by the recipient of the message".

So, influencers are going to be analysed to understand if they are seen as credible and reliable for information and how these factors provide satisfaction to their followers. The theory in itself proposes that people are more likely to be persuaded when the source of a message presents itself as credible. Here, it would be determined if the personality traits and characteristics of these influencers would pose a great foundation or basis for the believability of the influencers by the opinion followers (those being influenced).

\section{Formulation of hypothesis}

To locate influencers, for example, Katz and Lazarsfeld (1955, p.147) employed the questions such as "Have you recently been asked your advice about...?" and "Compared with other women belonging to your circle of friends, are you more or less likely to be asked your advice on...?" Subsequent research often criticized that these questions were not sufficient to measure the concept (e.g., Katz, 1957). Therefore, more complex scales evolved, and completely different methods emerged as well. From a social science perspective, Weimann and colleagues (2007) distinguished six traditional methods of measuring opinion leadership: (1) according to a person's formal position or (2) their reputation, (3) by observing the communication patterns in a community, (4) through self-designation by responding to items in an opinion leadership scale, (5) sociometric by analyzing the social network structure of a group, and (6) by asking key informants. In researches that had been conducted, four basic techniques have been successfully tested: socio-metric methods, interviews with key informants, observations, and self-designating techniques (Jacoby, 1974; Rogers and Cartano, 1962; Weimann, 1994) cited in (Langner, Hennigs \& Wiedmann, (2013). Of these methods, self-identification techniques are the most popular method as they can easily be administered in surveys cited in (Langner, Hennigs \& Wiedmann, (2013).

In political communication, several efforts have been used in identifying and measuring the disposition of opinion leadership and have centred on the scale of 'personality strength' (Noelle-Neumann, 1985; Weimann, 1991; Weimann \& Brosius, 1994; Shah \& Scheufele, 2006). Personality strength is a trait of these individuals that cannot be disposed of because 
is the heart or core of influencers' behaviour; it is a reflection of their confidence in leadership roles, their talent for forming others' opinions, and their self-perceived influence on social and political outcomes. Weimann (1991) successfully validated the scale by finding that those higher in 'personality strength' held central network positions and engaged in more communication activity. This validation leads to the first hypothesis:

$\mathrm{H}_{1} \quad$ Influencers with high personality attributes exert greater influence on their followers than those with low personality attributes.

Using the same Weimann's scale, Shah and Scheufele (2006) corroborated that opinion leadership is primarily explained by dispositional characteristics such as self-assuredness and innovativeness. When it comes to public affairs, those who are more knowledgeable are likely to be highly motivated to take part in the talks, and therefore, to expect a psychological reward for such actions. Political knowledge and commitment are to be predictors of opinion leadership in the issue sphere of politics; just as personal involvement and product familiarity are for the sphere of consumption (Rogers \& Shoemaker, 1971). Political knowledge and involvement alone may not be enough for assuming opinion leadership unless the individuals are equipped with competence in disseminating and influencing others using a medium of choice. Based on the review of the literature, the following hypotheses were generated:

$\mathrm{H}_{2} \quad$ Influencers with high personality traits and social attributes have greater credibility and thus exert greater influence on their followers than those with lower personality traits, social characteristics and lower credibility.

$\mathrm{H}_{3} \quad$ There is no significant relationship between influencers' communication ability and the level of impact they have on their followers.

Interestingly, opinion leader can assume the role of a follower at the same time (Jung \& Kim, 2016). This is one of the dynamics that makes influencers so successful: that they can be consumers themselves. Individuals can easily be influenced by opinion givers/seekers that follow mass media closely, either by personally trying products/services or comparing social media messages to their own value systems, and conveying these messages or endorsements to others in their community. With this, the study intends to investigate the level of impact of the influencers' political or marketing messages on their followers. Based on the review of the literature, the following hypothesis was generated:

$\mathrm{H}_{4} \quad$ There is no significant difference between the level of impact that political influencers have on their followers and the level of impact marketing influencers (mavens) have on their followers

\section{METHODOLOGY}

The data to test these hypotheses was collected from twitter accounts of the influencers after a baseline study had been conducted on the activities of the influencers and the intensity of their tweets. This study adopted mixed methods consisting of survey method with an online questionnaire as the instrument of collecting data as well as content analysis was adopted in the study. A total of seven social media influencers whose contents focus on the themes of Politics, Advocacy and Marketing were purposefully involved in this study. Respondents included individuals who were the followers of these influencers and who intended to participate in the survey after the link to the survey had been shared by the influencers. The population of the study as it was identified on the 5th of March, 2019 showed that about 611 , 400 individuals were the followers of the seven identified influencers on Twitter. Therefore, 
for the sake of statistical convenience as it concerns the management of complex primary data and large population like this study, the researcher used the Israel model (1992) to statistically determine the sample size statistically. Based on the $95 \%$ confidence level and the Israel (1992), population size table for the population greater than 100,000 as in this case is 400 constituted online followers mainly youths within the ages 18-35 of the influencers on Twitter. So, for the content analysis, posts were selected from and analysed from the timeline of each of the seven selected influencers using the constructed week method of two weeks from each of the influencers across three months. The tweets from each of the influencers' timeline were selected purposively based on the comments of the followers under them with scrutiny of such thread of tweets containing elements of communication strategies. This study adopted a non-probability sampling procedure of quota, simple random sampling as well as snowball sampling methods.

The researcher adopted these procedures because the questionnaire was administered online through the identified influencers. Seven social media influencers were systematically identified across the three categories of influencers owing to their popularity and the political undertone of their online activity. So, the number of followers selected from each of the identified influencers depended on the total number of followers each of them had. Again, the selection of the respondents from the followers of each identified influencers was determined by the numbers of influencers in each category. The following are the selected influencers; Dr.PamPam (@thepamilerin), The AjeButter of Lagos (@Theajebutter103), EbukaAkara (@ebuka_akara), Falilat (@Falilatt_),DADDY THE BAALE (@kingtanda),WHAYASAY (@iamwillsteel), \#hashtagMFR (@hashtagMFR). So, each of the identified influencers was asked to post on their timeline or wall the links to the questionnaire so that their followers could specifically fill it.

This study, therefore, used a two-week constructed sampling of all tweets posted on the timeline of the Twitter influencers between March and May, 2019. The tweets selected cut across various activities of the influencers; marketing, political and advocacy. Tweets were randomly selected from the timeline of the influencers and were selected each day of the week twice (i.e. Two (2) Sundays, Mondays, Tuesdays, Wednesdays, Thursdays, Fridays, and Saturdays) within the time frame selected for the study which then resulted in a 14-day collection of tweets. The constructed week sampling technique was employed to draw tweets for the study to understand the communication strategies used by the influencers. A total of 14 tweets were systematically selected over three months. Two weeks were selected from the three months' study period. From the two weeks, two posts per day for the 14 days of the two weeks were systematically selected for communication ability analysis covering the three categories of influencers. Items on the personal characteristics of the influencers were included such as innovativeness, expertise, self-confidence, manoeuvring, dogmatism, assertiveness. Social attributes of the influencers, also such as a social tie, gregariousness, strategic social location were included. Social media posts of the influencers ranging from its frequency, types, politeness, purpose; the language was not left out.

For the content analysis, based on Dodd \& Collins, (2017) study, they identified some message strategy used online in communicating: informative, facilitative, persuasive and cooperative approach. Tweets of the influencers that possess the informative strategy present unbiased facts using neutral language and allow audience members to draw their conclusions. A facilitative approach allows people to act in ways they are already predisposed to by making resources, such as money, available. A persuasive approach appeals to emotion anc 
Number 2

may involve language that expresses a particular point of view. These messages include a call to action. Also, the cooperative strategy showed tweets that suggested the "we" language, but it is designed to bring people together in enlightened self-interest. In the quantitative arm of this study which focused on the followers, a semi-structured self-administered online survey was deployed using Google Forms ${ }^{\circledR}$. The survey was designed in three templates for each of the themes of the study and the links to these themes were shared with the respective social media influencers earlier identified. Data were collected for the content analysis of the tweets by using the constructed coding schedule that consisted of specific variables and their categories relating to communication strategies. The coding schedule is attached as

For the qualitative arm of the study, a content analysis, which involved the use of a coding schedule to analyse the tweets of the influencers across selected measures/concepts was employed. The themes being looked out for were listed and coded accordingly.

\section{RESULTS AND DISCUSSION}

H1: Influencers with high personality attributes exert greater influence on their followers than those with low personality attributes.

Table 4.1: Comparison between Personality Attributes of Influencers and Extent of Influence on their followers

\begin{tabular}{|c|c|c|c|c|c|}
\hline $\begin{array}{l}\text { Personality } \\
\text { Attributes } \\
\text { Political (137) }\end{array}$ & $\mathrm{N}$ & Mean & $\begin{array}{l}\text { Std. } \\
\text { Deviation }\end{array}$ & T-test & $\mathrm{P}$ \\
\hline High & 83 & 37.29 & 7.22 & $4.01(\mathrm{df}=135)$ & $<0.001$ \\
\hline Low & 54 & 31.91 & 7.97 & & \\
\hline
\end{tabular}

Advocacy

$(\mathrm{N}=115)$

High

58

55.40

6.25

$3.32(\mathrm{df}=95.09) \quad 0.001$

Low

9.75

Marketing

$(\mathrm{N}=140)$

$\begin{array}{llllll}\text { High } & 86 & 6.58 & 2.57 & 3.07(\mathrm{df}=138) & 0.003 \\ \text { Low } & 54 & 5.28 & 2.23 & & \end{array}$

The result of the t-test presented in the table 4.1 showed that personality attributes of influencers have a significant effect on the extent of influence their online activities exert on their followers. Influencers with high personality attributes exert a larger extent of influence on followers compared to those with lower personality attributes as shown in the table 4.1.

The mean extent of influence score was higher for influencers with higher personality traits compared to those with lower personality traits in all the research themes, as a result of which it was statistically significant in all groups ( $p$ value $<0.005$ ). For instance, there was a statistically significant difference between the mean level of influence on followers for political influencers with high personality attributes compared to those with lower personality attributes $(\mathrm{t}=4.01, \mathrm{df}=135)$. A similar observation was made to advocacy $(\mathrm{t}=3.32, \mathrm{df}=$ 95.09). 
Number 2

Thus, higher strength of personality attribute significantly contributes higher level of influence on followers compared to a lower strength of personality attribute.

$\mathrm{H}_{2}$ Influencers with high personality traits and social attributes have greater credibility and thus exert greater influence on their followers than those with lower personality traits, social attributes and lower credibility.

Table 4.2: Relationship betweenInfluencers' Personality Traits and Social Attributes and Extent of Influence on their followers

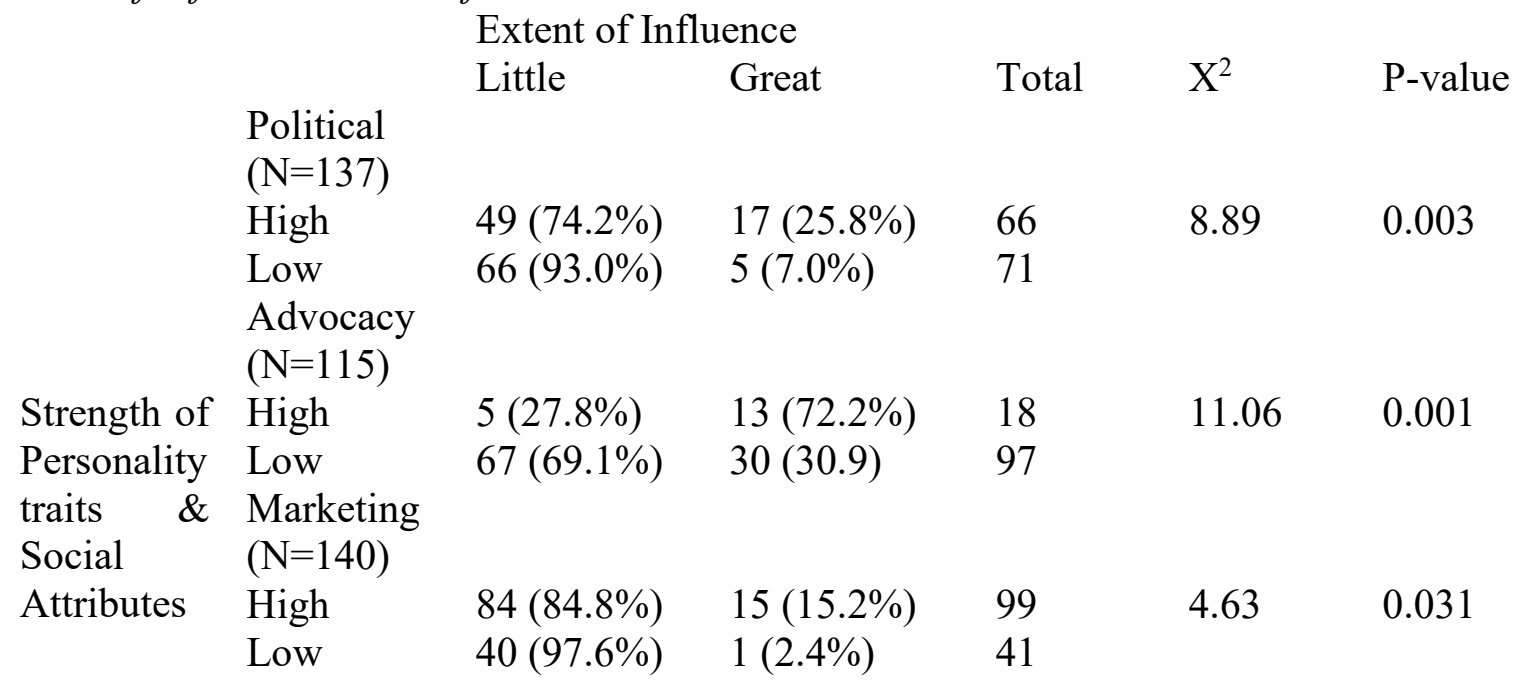

In table 4.2 above, forty-nine (74.2\%) of the influencers who had high personality and social attributes had little extent of influence on their followers compared to $17(25.8 \%)$ who had a great level of influence on their followers $\left(\mathrm{X}^{2}=8.89, \mathrm{p}=0.003\right)$. This suggests that a higher personality traits and social attributes of the political influencers do not necessarily in turn result into greater level of influence. Though, the strength of the two parameters (personality traits and social attributes) separately may have a positive relationship on extent of influence as established by the results of the interactive effect of the personality traits and social attributes of the influencers. The result showed that the social attributes of the influencers does not predict the level of influence.

A similar observation was made among the marketing respondents where $84(84.8 \%)$ of the influencers who had high strength of personality traits and social attributes $\left(X^{2}=4.63, p\right.$ value $=0.031$ ). However, the results obtained from the advocacy respondents showed that a high strength of personality traits and social attributes results in higher extent of influence on respondent. This means there is a significant relationship between the combined factors and the level of influence of advocacy influencers on their followers $\left(X^{2}=11.06, p\right.$ value $\left.=0.001\right)$.

So, in general, fewer respondents were classified to have great level of influence exerted on them (especially for political and marketing respondents) unlike in the advocacy theme. However, this does negate the fact that there was an observed relationship between influencers' personality traits and social attributes and extent of influence on their followers ( $\mathrm{p}$ value $<0.05$ across all themes).

H3: There is no significant relationship between influencers' communication ability and the level of impact they have on their followers 
Number 2

Table 4.3: Relationship betweenInfluencers' Communication Ability and the Level of Impact on their followers

\begin{tabular}{|c|c|c|c|c|c|}
\hline & \multicolumn{2}{|c|}{ Parameters of Influence } & \multirow{3}{*}{ Total } & \multirow[b]{2}{*}{$X^{2}$} & \multirow{3}{*}{ P-Value } \\
\hline & Likes & Comments & & & \\
\hline & \&Retweets & \&Hashtags & & & \\
\hline Informative & $3(33.3 \%)$ & $6(66.7 \%)$ & 9 & 2.8 & 0.942 \\
\hline \&Facilitative & & & & & \\
\hline $\begin{array}{l}\text { Persuasive } \\
\text { \&Cooperative }\end{array}$ & $4(80.0 \%)$ & $1(20.0 \%)$ & 5 & & \\
\hline \&Cooperative & & & & & \\
\hline Total & 7 & 7 & 14 & & \\
\hline
\end{tabular}

As shown in table 4.3, the content analysis result carried out on the influencer's tweet was used to test this hypothesis. Communication ability was measured using the informativeness, facilitativeness, persuasiveness and cooperativeness. On the other hand, the level of impact on followers was measured using likes, retweets, comments and hashtags generated by such tweets. Only $3(33.3 \%)$ of the informative and facilitative tweets resulted in the followers liking or retweeting while $6(66.7 \%)$ resulted in the followers further commenting or putting up an hashtag for the tweet. Four $(80.0 \%)$ of the persuasive tweet led to likes and retweets, while only one resulted in followers commenting or putting up an hashtag on Twitter. So, no statistically significant relationship was observed between communication ability and level of impact ( $\mathrm{p}$ value $>0.05$ ) as seen in the Table 4.3.

H4 There is no significant difference between the level of impact that political influencers have on their followers and the level of impact marketing influencers (mavens) have on their followers

Table 4.4: Comparison between the Level of Impact of Political Influencers and Marketing Influencers (mavens) on their Followers

$\mathrm{N} \quad$ Mean

Level of Influence of 137

Marketing Influencer

Level of Influence of $140 \quad 34.42 \quad 8.136$
Std. Deviation

11.518

46.91 
This study sought to examine if the social media influencers have an impact on their followers in online community using solely Twitter for the purpose of this research. This analysis was informed on the current literature on impact of influencers on Instagram and YouTube on their followers as conducted by Nandagiri \& Philip, (2018). However, for this study, Twitter was specifically chosen. With the help of mixed methods, it was concluded that the work of an influencer is positive and that they do have an impact on the followers.

Through the findings, on communication strategies of the influencers, it was discovered that the informativeness of the posts, facilitative nature it consists of and the persuasiveness strategies all form how the followers would receive the message being passed across to attract their followers. Cooperativeness was found to be lacking and was rated low in the posts of the influencers. Thus, social media influencers can better impact their followers by posting informative posts, persuading them and facilitating them through their posts.

Also, it was discovered that the extent of influence a marketing influencer will have on his followers is as a result of the reviews of brand or products he posts and not through recommendations. The results showed social media influencers exert a relatively acceptable level of influence on the opinions and decisions of their followers. Across the research themes, liking an influencers' post on a helpful political issue was observed as a major opinion behaviour indicator which indicates the extent of influence such post have on the individual. The fact that an influencers post created awareness on major social issues by creating a movement with the use of hashtag on the issue was observed as the major extent of influence measure among the advocacy group.

In other words, the proportion of respondents who had high strength of personality and also great extent of influence on their followers was low compared to those who had high strength of personality but little extent of influence. A possible explanation is because there were more respondents who were considered to have little extent of influence exerted upon them across all the themes (e.g. there were 115 in the little extent of influence category compared to only 22 in the high level of influence category).

And finally, study found that both the social attributes and personality traits of political influencers contribute significantly to the level of influence they exert on their followers.

Thus, it is concluded that online influencers have positive impact on their followers. Importantly, many respondents were reluctant to answer the questionnaires because of the subject matter and the particular platform (Twitter) that was used. Some of the respondents refused to click on the link as a result of unavailability of internet connection and not wanting to exhaust their monthly data subscription. In relation to this, using only one platform as the basis for this study cannot allow a valid and reliable generalization about other social media platforms that were not involved in this study.

The phenomenon of social media influencer is just fast rising in the society. Few researches have been carried out on its benefits and importance to the society at large. It is on this note that it is recommended that this phenomenon be given much consideration as a skill can be developed into becoming an influencer. This study offers recommendations that social media influencers can better impact their followers by putting up informative, persuasive and facilitative posts. This means that the social media influencers across all categories should be conscious of their message strategy or writing skills so they can exert a greater influence. Influencers should post impactful messages that could have greater impact for the continuity 
Number 2

of exerting influence on their followers. Also the government should take note of the activities of the social media influencers especially the political and advocacy influencers because they pose a great skill in mobilizing their followers into doing certain things they do not even wish to do. Thus, awareness on a new policy about to be implemented can be released to the social media influencers. The personality traits and social attributes of the influencers that were supported by the findings should be enhanced by influencers in order to boost their capacity for wining more followers. Foremost, this study might be the first study regarding impact of social media influencers on their followers' marketing knowledge, political adaptability and advocacy knowledge, influencer types and influencers' personal traits across three specific themes.

The results can be served as a start point for future research for whoever aims to go deeper and more detailed in the same themes or has interest in the impact of an influencer marketing on other important social issues. Yet the previous studies have not pointed out the difference in the activities that lead to an impact on followers. Other studies should be carried out on other demography since the young adults are not the only ones exposed to the influencers. Such further studies should aim at confirming the extent to which social media influencers translate their online followership to offline political/social decisions/behaviours and influence.

\section{REFERENCES}

Akinlade, A., (2015). The Influence of Social Media on the Voting Behaviour of the Youth in South East Nigeria.Unpublished M.Sc. Dissertation.Department of Mass Communication, University of Nigeria, Nigeria.

Anaeto, S. G., Onabajo, O. S., \&Osifeso, J. B. (2008).Models and theories of mass communication, USA: African Renaissance Books Inc.

Anyanwu, E. U., OssaiOnah, \&Iroeze, P. (2013). Use of Social Media Tools Among Nigerian Undergraduates in Three Selected Tertiary Institutions in Imo State, Nigeria. Journal of Information and Knowledge Management. 4(2), 46-51

Bello, B., (2018). Social Media Influencers in Nigeria: How They Make it to the Top. Retrieved March 21, 2019 from, http://www.google.com/amp/s/ideaslane.com/2018/04/20/social-media-influencers-innigeria-how-they-make-it-so-far/amp/

Casaló, L. V., Cisneros, J., Flavián, C., \&Guinalíu, M. (2009).Determinants of success in open source software networks.Industrial Management \& Data Systems, 109(4), 532 549

Casaló, L. V., Flavián, C., \& Ibáñez-Sánchez, S. (2018). Influencers on Instagram: Antecedents and consequences of opinion leadership. Journal of Business Research. 110 Retrieved March 12,2019 from http://doi10.1016/j.jbusres.2018.07.005

Chiemela, A., Ovute A., Obochi, C. (2015). The influence of the social media on the Nigerian youths: Aba residents experience. Journal of Research in Humanities and Social Science 3(3), 12-20. RetrievedFebruary 10, 2019 fromwww.questjournals.org 
Dodd, D. M., \& Collins, S. J. (2017). Public relations message strategies and public diplomacy 2.0: An empirical analysis using Central-Eastern European and Western Embassy Twitter accounts. Public Relations Review.http://dx.doi.org/10.1016/j.pubrev.2017.02.004

Ekueme, M., \&Folarin, S. F. (2017). Role of Social Media in Electioneering: The Case of the Nigerian 2015 Presidential Election. Paper presented at the e-conference Covenant University Conference on e-Governance in Nigeria-CUCEN2017 RetrievedJanuary 23, 2019from http://eprints.covenantuniversity.edu.ng/10323/\#.XJUg2dUo-w4

Hovland, C. I., Janis, I. L. and Kelley, H. H. (1953). Communication and Persuasion; Psychological Studies of Opinion Change. New Haven:Yale University Press.

Israel, D. G. (1970).Determining Sample Size,Program Evaluation and Organizational Development, IFAS, University of Florida.

Jung, K., \&Kim, Y. (2016). Are You an Opinion Giver, Seeker, or Both? Re-Examining Political Opinion Leadership in the New Communication Environment.International Journal of Communication. 10, 4439-4459. Retrieved February 23, 2019 from:http://ijoc.org

Jungnickel, K. (2018). New Methods of Measuring Opinion Leadership: A Systematic, Interdisciplinary Literature Analysis. International Journal of Communication. 12. 2702-2724 http://ijoc.org.

Katz E, Lazarsfeld P., F. (1955). Personal Influence: The part played by people in the flow of mass communications. London:Transaction Publishers

Katz, E. (1957). The Two-Step Flow of Communication: An Up-to-Date Report on a Hypothesis. Public Opinion Quarterly.21 (1), 61-78

Kononova, A., \& Akbar, M. (2015). Interpersonal Communication, Media Exposure, Opinion Leadership, and Perceived Credibility of News and Advertising During the December 2012 Parliamentary Election in Kuwait. International Journal of Communication, 9, $1206-1228$.

Lazarfield, P. F., Berelson, B., \&Gaudet, H. (1948).The people's choice: How the Voter Makes Up His Mind in a Presidential Campaign. New York: Columbia University Press.

Lazarsfeld, P., Berelson, B., \&Gaudet, H. (1948).The People's Choice. New York: Columbia University Press.

Nandagiri, V., \&Philip, L. (2018). "Impact of Influencers from Instagram and Youtube on their Followers", International Journal of Multidisciplinary Research and Modern Education, 4(1), 61-65 
Number 2

National Communication Commission (2019), Nigeria: number of internet users 2017-2023. RetrievedJanuary 20, 2019 from https://www.statista.com/statistics/183849/internetusers-nigeria/

Nnanyelugo, O \& Nwafor, K.A. (2013). Social Media and Political Participation in Nigeria During the 2011 General Elections: The Lapses and the Lessons. Global Journal of Arts Humanities and Social Sciences, 36, 123-134

Noelle-Neumann, E. (1985). Identifying Opinion Leaders. Paper presented at the 38th Annual Convention of the European Society of Market Research, Wiesbaden, Germany.

Olasinde, E. A. (2014). An Analysis of the Influence of Social Media Sites on Nigerian Undergraduates.Education \& Science Journal. 4(1), 53-65. RetrievedMarch 22, 2019from www.internationalpolicybrief.org

Rogers, E. M., \& Shoemaker, F. F. (1971).Communication of Innovations.Free Press: New York.

Self, C. C. (2007)."Credibility". In Salwen, Michael B.; Stacks, Don W.(2007) An Integrated approach to communication theory and research. London: Sage.

Shah, D. V., \&Scheufele, D. A. (2006).Explicating opinion leadership: Nonpolitical dispositions, information consumption, and civic participation.Journal ofPolitical Communication, 23, 1-22. doi:10.1080/10584600500476932

Tokunbo, A., \& Felix, A. (2013). Nigerian Youths and Social Media: Harnessing the Potentials for Academic Excellence. Journal of Business and Management, 2(5), 345348

Weimann, G. (1991). The influentials: Back to the concept of opinion leaders? Public Opinion Quarterly, 55, 267-279. 